\title{
Causes of death in children diagnosed with non-Hodgkin's lymphoma between 1974 and 1985
}

\author{
C M Robertson, C A Stiller, J E Kingston
}

\begin{abstract}
An investigation has been undertaken of 479 deaths occurring up to the end of 1990 among 883 patients diagnosed with non-Hodgkin's lymphoma from 1974 to 1985 who were included in the population based National Registry of Childhood Tumours. The objectives were to perform a descriptive analysis looking particularly at the deaths not directly due to non-Hodgkin's lymphoma, to determine the frequency of the different causes of death and to study the trends over time.
\end{abstract}

Among the 476 patients with sufficient information for the cause of death to be established, these were: non-Hodgkin's lymphoma, 377 (79\%); treatment related (other than second primary tumour), $86(18 \%)$; second primary tumour, $10(2 \%)$; and other, three (1\%). The proportion of all deaths not directly due to non-Hodgkin's lymphoma increased from $15 \%$ for those diagnosed during 1974-6 to $32 \%$ for those diagnosed during 1983-5.

Among the 86 treatment related deaths, the more precise causes were bacterial infections, $26(30 \%)$; viral and other infection, $14(16 \%)$; metabolic, 19 (22\%); renal, eight (9\%); anaesthetic related, seven $(8 \%)$; respiratory, four $(5 \%)$; cardiac, three (3\%); graft versus host disease, three (3\%); and other, two $(2 \%)$. Treatment related deaths from infection accounted for $27(6 \%)$ of all patients diagnosed in 1974-9, and $13(3 \%)$ in 1980-5. Treatment related deaths not due to infection occurred in $23(5 \%)$ of those diagnosed in $1974-9$ and 23 $(6 \%)$ in $1980-5$. Five treatment related deaths, including four anaesthetic related deaths, were identified as avoidable. Some of the deaths from metabolic and renal disease may also have been avoidable.

Only 11 deaths have been recorded more than five years after diagnosis, six being due to second primary tumours. As follow up is relatively short for patients diagnosed more recently, further deaths from second malignancies and treatment related cardiovascular problems may well occur.

A substantial number of children with non-

University of Oxford, Department of Paediatrics, Childhood Cancer Research Group, 57 Woodstock Road Oxford OX2 6H C M Robertson C A Stiller

J E Kingston

Correspondence to: Mr Stiller.

Accepted 31 July 1992
Hodgkin's lymphoma die of treatment related causes. Deaths from infection have decreased in line with the overall improvement in survival rates. Other treatment related mortality has remained constant. Further improvements in survival for childhood non-Hodgkin's lymphoma will depend on maintaining the fine balance between the therapeutic value of intensive treatment and its potential harmful effects.

(Arch Dis Child 1992;67:1378-83)
A detailed analysis of survival rates for children in Britain with cancer diagnosed from 1971 to 1985, using data from the population based National Registry of Childhood Tumours (NRCT), has been published.' As expected, following the advances that have been made in treatment, this showed a dramatic improvement in survival in most diagnostic groups. One of the most striking results was the increase in the five year survival rate for children with nonHodgkin's lymphoma from $24 \%$ in the mid 1970 s to $70 \%$ in the mid 1980 s. As survival rates improve it is increasingly important that the nature and frequency of the short and long term effects of cancer treatment are determined. The effects of treatment have often been studied at individual centres and in clinical trials, but few results are available from population based data. Long term effects have been the subject of a number of population based studies in Britain ${ }^{2}$; multicentre studies of late effects have been carried out by the Late Effects Study Group ${ }^{4}$ and investigations are in progress by the late effects group of the United Kingdom Children's Cancer Study Group (UKCCSG).

In large population based studies it is difficult to obtain the necessary clinical details to determine the morbidity associated with the treatment of cancer. It is more practicable to study mortality and use the cause of death as an outcome measure. Obviously this will only detect the more severe effects of treatment, but none the less it is particularly important to have information on such effects. Hawkins et al have shown that studying the causes of death more than five years after diagnosis is an effective way of discovering severe treatment related effects and also potentially preventable deaths. ${ }^{2}$ It is more difficult to determine the causes of earlier deaths as tumour and treatment effects can be difficult to separate. There have been few studies of deaths among children with cancer within five years of diagnosis. A small, single institution study of 37 deaths in children with acute lymphoblastic leukaemia concluded that five of the deaths occurring during induction or in primary remission, and not due to the malignancy itself, might have been prevented by appropriate diagnosis and treatment. ${ }^{6}$

The underlying cause of death recorded on the death certificate may well be unreliable. ${ }^{7}$ Therefore it is necessary in a study of causes of death to glean as much information as possible from other sources, particularly hospital records.

The purpose of our study was to investigate the causes of death among children with nonHodgkin's lymphoma included in the above mentioned analysis of survival rates. Our objec- 
tive was to carry out a descriptive analysis, paying particular attention to the deaths not directly due to the original tumour and to determine the frequency of the different causes of death and also to observe any trends with time. We hoped to be able to identify potentially avoidable deaths. We chose to investigate children with non-Hodgkin's lymphoma as they represent a large group for which there has been a striking improvement in survival during the study period, and many of whom have received intensive treatment, often within the UKCCSG non-Hodgkin's lymphoma trials. ${ }^{89}$

\section{Subjects and methods}

The NRCT is a population based registry of cancer in children under the age of 15 years which covers the whole of Great Britain. Cases are ascertained from national and regional cancer registries, specialist regional children's tumour registries, notifications to clinical trials, and the UKCCSG. The registry receives death certificates for all deaths occurring in Britain under the age of 20 with a neoplasm coded as the underlying cause of death. At about five years from diagnosis the medical records of children in the registry are checked to confirm the diagnosis and to obtain a brief outline of treatment and follow up. The survivors, together with any children who have died but for whom no death certificate has been received, are flagged in the National Health Service Central Registers so that the NRCT receives a copy of the death certificate for any patient who has already died or who dies subsequently.

For this study non-Hodgkin's lymphoma was defined as all diagnoses in groups IIb- $d$ in the Birch and Marsden classification, ${ }^{10}$ including Burkitt's lymphoma and unspecified lymphoma. There were 883 children in the NRCT with non-Hodgkin's lymphoma diagnosed during 1974-85. Cause of death was studied in all 479 patients from the series who had died at any time from diagnosis up until the end of 1990.

The main source of information was the files held by the NRCT, which include death certificates, cancer registrations, UKCCSG registrations and follow up forms, and abstractions from general practitioner notes and hospital notes. When the information in the files was inadequate, and also in all instances where the circumstances of death were unusual or the death was judged not to be due to nonHodgkin's lymphoma further information was sought. This was obtained from hospital notes and necropsy reports, from the files of the UKCCSG for a few children included in UKCCSG trials, and in a few instances by direct questions to the consultant.

The sources of information used on the 479 deaths in the study were: death certificates (472) (for seven patients who died abroad, no death certificate was available), routine follow up information (474), hospital notes (115), necropsy reports (69), and information from trials (seven).

The full series of 883 children was classified by primary site as follows: head and neck, 221; mediastinal and other thoracic, 187; intraabdominal, 214; other specified sites, 78; and unspecified, 183, mostly children with widely disseminated disease at diagnosis in whom a primary site could not reliably be identified.

For each death the following information was collected: (A) the International Classification of Diseases eighth and ninth revisions ${ }^{11} 12$ code for underlying cause of death on the death certificate, as coded by the Office of Population Censuses and Surveys for England and Wales and by the Information and Statistics Division of the Scottish Health Service. (B) The underlying cause of death, based on all available information, assigned by us to one of the following broad categories: original tumour (non-Hodgkin's lymphoma); treatment related (other than second primary tumour); second primary tumour; violent or accidental death; other unrelated medical condition; and insufficient information. This classification is based on the classification of cause of death used by Hawkins et al in their paper on late deaths. ${ }^{2}$ (C) Evidence of presence of a tumour at time of death. (D) Site and date of first relapse.

The following conventions were used in assigning the deaths to these broad categories. Bronchopneumonia was often given as the cause of death in children who had gradually deteriorated with recurrent tumour; these deaths were all coded as tumour deaths rather than infection. If a child died from infection while receiving chemotherapy or within six months of stopping treatment the death was coded as treatment related. The death of one patient who had had a splenectomy and subsequently died of pneumococcal meningitis while in remission was also coded as treatment related. When death occurred from any cause and there was insufficient evidence to determine whether the patient had active disease at the time, then the death was coded as insufficient information. A second doctor reviewed all cases where the cause of death was coded as not due to the original tumour or where there was uncertainty about the cause of death.

Actuarial survival analysis was performed to determine the risks of dying from a particular cause of death in relation to type of treatment centre and whether the child had been included in a clinical trial. Children who did not receive any form of treatment or have a biopsy sample taken were excluded from the analyses of the mortality rates. In calculating rates for particular subcategories of cause of death, patients dying of causes other than that in question were censored at the time of death.

\section{Results}

Table 1 shows the causes of death as assigned by us using all available sources of information. There were three deaths for which the information available was insufficient to determine the cause of death. The numbers of deaths due to specific causes have been expressed as percentages of the remaining 476 deaths. Using all available sources we found that $377(79 \%)$ died from non-Hodgkin's lymphoma and 99 (21\%) died from other causes. Ten (2\%) children died from second primary tumours; these consisted of six with acute myeloid leukaemia, two with 
Table 1 Comparison of cause of death as coded by the Office of Population Censuses and Surveys on the death certificate and cause of death determined using all available sources of information

\begin{tabular}{|c|c|c|c|c|c|c|c|}
\hline \multirow{2}{*}{$\begin{array}{l}\text { Cause of death on } \\
\text { death certificate }\end{array}$} & \multicolumn{7}{|c|}{ Cause of death using all available information } \\
\hline & $\begin{array}{l}\text { Original } \\
\text { tumour }\end{array}$ & $\begin{array}{l}\text { Treatment } \\
\text { related }\end{array}$ & $\begin{array}{l}\text { Second } \\
\text { primary } \\
\text { tumour }\end{array}$ & Accident & $\begin{array}{l}\text { Other } \\
\text { medical } \\
\text { cause }\end{array}$ & Unknown & Total \\
\hline $\begin{array}{l}\text { Non-Hodgkin's lymphoma } \\
\text { Acute lymphoblastic leukaemia } \\
\text { Unspecified leukaemia } \\
\text { Acute myeloblastic leukaemia } \\
\text { Other or unspecified neoplasm } \\
\text { Other cause } \\
\text { Died overseas }\end{array}$ & $\begin{array}{r}293 \\
43 \\
3 \\
1 \\
24 \\
6 \\
7\end{array}$ & $\begin{array}{r}59 \\
10 \\
1 \\
-8 \\
8 \\
-\end{array}$ & $\begin{array}{l}-1 \\
\overline{5} \\
4 \\
-\end{array}$ & $\begin{array}{l}\bar{z} \\
\overline{-} \\
\frac{1}{-}\end{array}$ & $\begin{array}{l}\frac{1}{-} \\
\frac{1}{1} \\
-\end{array}$ & $\begin{array}{l}3 \\
= \\
= \\
-\end{array}$ & $\begin{array}{r}356 \\
54 \\
4 \\
6 \\
36 \\
16 \\
7\end{array}$ \\
\hline Total & $377(79 \%)^{*}$ & $86(18 \%)^{*}$ & $10(2 \%)^{*}$ & 1 & 2 & 3 & 479 \\
\hline
\end{tabular}

${ }^{*}$ Number in parenthesis is expressed as a percentage of the 476 patients with known cause of death.

osteosarcoma, and two with astrocytoma. One child died in a road traffic accident which was completely unrelated to the non-Hodgkin's lymphoma. The two children who died from other disorders had underlying immunodeficiencies (Wiskott-Aldrich and Bloom's syndrome) and it was judged that they died from these disorders rather than from the non-Hodgkin's lymphoma or its treatment.

Table 1 also shows the underlying cause of death as given on the death certificate. In most patients the death certificate code and the 'all sources' code were consistent. Nine of the 10 second malignancies had been coded correctly on the death certificate. There were 32 patients, however, where the death certificate gave the cause of death as a neoplasm other than nonHodgkin's lymphoma or leukaemia (including a wide variety of tumours from thymoma to osteosarcoma) when the 'all sources' code was not a second primary tumour. Seventy eight of 86 deaths judged to be treatment related on the basis of all available evidence were coded on the death certificate as death due to the tumour. This can be partly explained by an anomaly in the International Classification of Diseases eighth revision ${ }^{11}$ (used for coding deaths occurring before 1979) in which any death caused by treatment was coded to the disease for which the treatment was being given. This was amended in the International Classification of Diseases ninth revision ${ }^{12}$ so that death caused by an untoward effect of treatment should be coded as such. In this study only one (3\%) of the 35 treatment related deaths that occurred before 1979 was coded to a non-tumour cause on the death certificate, compared with seven (14\%) of the 51 that occurred from 1979 onwards. Thus although the proportion of treatment related deaths assigned to a non-tumour cause increased

Table 2 Nature of treatment related deaths

\begin{tabular}{|c|c|c|c|c|}
\hline Subcategories & $\begin{array}{l}\text { No during } \\
\text { first induction }\end{array}$ & $\begin{array}{l}\text { No in } \\
\text { remission }\end{array}$ & $\begin{array}{l}\text { No in } \\
\text { relapse }\end{array}$ & $\begin{array}{l}\text { Total } \\
\text { No }(\%)\end{array}$ \\
\hline \multicolumn{5}{|l|}{ Infection } \\
\hline Bacterial & 11 & 5 & 10 & $26(30)$ \\
\hline Viral plus other & 2 & 8 & 4 & 14 (16) \\
\hline Metabolic disorder & 19 & 0 & $\mathbf{0}$ & $19(22)$ \\
\hline Anaesthetic related & 5 & $\mathbf{0}$ & 2 & $7(8)$ \\
\hline Renal disease & 7 & $\mathbf{0}$ & 1 & $8(9)$ \\
\hline Cardiac disease & 0 & 2 & 1 & $3(3)$ \\
\hline Respiratory disease & 2 & 2 & 0 & $4(5)$ \\
\hline $\begin{array}{l}\text { Graft-versus-host } \\
\text { disease }\end{array}$ & 0 & 3 & 0 & $3(3)$ \\
\hline Other & 2 & 0 & 0 & $2(2)$ \\
\hline Total No (\%) & $48(56)$ & $20(23)$ & $18(21)$ & $86(100)$ \\
\hline
\end{tabular}

with the change in coding practice, it remained low.

Table 2 gives an analysis of the 86 deaths considered to be due to treatment related factors. The subcategory with the largest number of patients was the group with infections; bacterial infections outnumbered viral and other infections by nearly two to one. There were no deaths from infection more than six months after chemotherapy had ended, except for one patient with pneumococcal meningitis thought to be related to a previous splenectomy. Other significant groups were the metabolic, anaesthetic, and renal deaths. Twelve of 19 metabolic deaths and four of eight deaths due to renal disease were in children with known abdominal primary tumours. These accounted for the fact that $26 \%$ of the deaths in this primary site group were treatment related compared with $18 \%$ overall. Table 2 also shows the number of deaths occurring during induction, in remission and in relapse. Over half $(48 ; 56 \%)$ of the treatment related deaths occurred during initial induction and only $20(23 \%)$ occurred during remission. A further $18(21 \%)$ occurred in patients undergoing treatment for relapsed disease and many of these were probably unavoidable. Table 3 describes the causes of the 86 treatment related deaths in more detail.

There were 19 deaths among children who had previously received a bone marrow transplant. Of these, 11 died from relapsed nonHodgkin's lymphoma. For the remaining eight children the causes of death were as follows: three graft versus host disease, three infections, one second primary tumour, and one cardiomyopathy.

Table 4 gives the number of deaths due to non-Hodgkin's lymphoma and other causes for four different time periods of diagnosis. The total number of deaths and the number of deaths from non-Hodgkin's lymphoma decreased over the study period, but the number of deaths from causes other than non-Hodgkin's lymphoma has remained nearly constant. Thus as a proportion of the total deaths, these increased from $15 \%(26 / 173)$ for the years of diagnosis $1974-6$, to $32 \%(20 / 62)$ for $1983-5$. The numbers in each category of deaths from causes other than non-Hodgkin's lymphoma are small but the data suggest that although the deaths from infection decreased with time, the treatment related deaths other than those from infection remained static within the period of follow up for the study. 
Table 3 Details of treatment related deaths

\begin{tabular}{|c|c|}
\hline Subcategory & Detailed cause of death \\
\hline \multicolumn{2}{|l|}{ Infection-Bacterial } \\
\hline Organism specified & $\begin{array}{l}9 \text { Escherichia coli septicaemia } \\
2 \text { pseudomonas septicaemia (one in perianal infection) } \\
2 \text { with mixed Gram negative plus streptococcal septicaemia } \\
1 \text { Staphylococcus aureus septicaemia } \\
2 \text { pneumococcal meningitis (one in splenectomy patient) } \\
1 \text { pseudomonas meningitis }\end{array}$ \\
\hline Unspecified & $\begin{array}{l}5 \text { septicaemia (one sialitis plus one perinanal infection) } \\
2 \text { pneumonia } \\
1 \text { peritonitis and colonic abscess } \\
1 \text { meningitis }\end{array}$ \\
\hline \multicolumn{2}{|c|}{ Infection-viral and other } \\
\hline Specified & $\begin{array}{l}2 \text { cytomegalovirus pneumonia } \\
2 \text { pneumocystis pneumonia } \\
2 \text { candidiasis } \\
2 \text { varicella } \\
1 \text { giant cell (measles) pneumonia } \\
1 \text { herpes simplex } \\
1 \text { herpes zoster }\end{array}$ \\
\hline Unspecified & $\begin{array}{l}1 \text { hepatitis } \\
1 \text { meningitis } \\
1 \text { encephalitis }\end{array}$ \\
\hline Metabolic disorder & $\begin{array}{l}8 \text { sudden death soon after laparotomy for extensive abdominal tumour (no chemotherapy) } \\
1 \text { sudden death soon after bronchoscopy and biopsy, extensive tumour } \\
9 \text { metabolic disturbance after first doses of chemotherapy } \\
1 \text { during operation for paracentesis }\end{array}$ \\
\hline Anaesthetic related & $\begin{array}{l}1 \text { during anaesthetic induction for mediastinal biopsy (superior vena cava obstruction before operation) } \\
1 \text { during anaesthetic for cervical lymph node biopsy (superior vena cava obstruction before operation) } \\
1 \text { during anaesthetic for peritoneal tap and bone marrow } \\
1 \text { inhaled gastric contents during anaesthetic for laparotomy for biopsy sample for abdominal mass } \\
1 \text { during anaesthetic for laparotomy for biopsy sample of abdominal mass } \\
1 \text { acute heart failure during operation for insertion of Hickman line, after first relapse } \\
1 \text { during anaesthetic induction for removal of Broviac catheter. Tracheal obstruction from } \\
\text { undiagnosed relapse }\end{array}$ \\
\hline Renal disease & $\begin{array}{l}1 \text { renal failure from high dose cytosine } \\
1 \text { renal failure following circulatory collapse, after an operation } \\
5 \text { renal failures soon after laparotomy for abdominal tumour with renal disease or obstructive nephropathy } \\
1 \text { renal failure, bilateral renal tumour, after only biopsy of shoulder mass }\end{array}$ \\
\hline Respiratory disease & $\begin{array}{l}1 \text { bilateral phrenic nerve palsies, after removal of mediastinal mass } \\
1 \text { bilateral pneumothoraces while ventilated after lymph node biopsy } \\
1 \text { respiratory arrest following thoracotomy for biopsy sample of mediastinal mass } \\
1 \text { pulmonary fibrosis from radiotherapy in patient with ataxia telangiectasia }\end{array}$ \\
\hline Cardiac disease & 2 cardiomyopathy, 1 adriamycin, and 1 unknown aetiology \\
\hline $\begin{array}{l}\text { Graft versus host disease } \\
\text { Other }\end{array}$ & $\begin{array}{l}3 \text { patients } \\
1 \text { acute brain degeneration six weeks after treatment started, ?drug toxicity } \\
1 \text { toxic epidermal necrolysis during induction, ?tobramycin }\end{array}$ \\
\hline
\end{tabular}

There were only 11 late deaths (more than five years after diagnosis) in the study and this explains why actuarial survival analyses were not required for interpreting the data in table 4 . Of these late deaths all but two were deaths other than from non-Hodgkin's lymphoma, six being caused by a second primary tumour. The distribution of the second primary tumour deaths by period of diagnosis, with relatively few second primary tumour deaths recorded so far among children diagnosed in 1980-5, can be explained by the fact that the latent interval for occurrence of secondary solid tumours is about 10 years. Therefore further late deaths from second malignancies are likely to occur. The

Table 4 Total number of cases of non-Hodgkin's lymphoma diagnosed, deaths from non-Hodgkin's lymphoma and deaths from causes other than non-Hodgkin's lymphoma by period of diagnosis. Three deaths with insufficient information have been excluded. Results given as No (\%) of total number of cases diagnosed in each calendar period

\begin{tabular}{lcccccc}
\hline & Year of diagnosis & & & \\
\cline { 2 - 7 } & $1974-6$ & $1977-9$ & $1980-2$ & $1983-5$ & Total \\
\hline $\begin{array}{l}\text { No of cases diagnosed } \\
\text { No of deaths due to non-Hodgkin's } \\
\text { lymphoma }\end{array}$ & 237 & 237 & 205 & 204 & 883 \\
$\begin{array}{l}\text { Total deaths not due to non-Hodgkin's } \\
\text { lymphoma }\end{array}$ & $147(62)$ & $117(49)$ & $71(35)$ & $42(21)$ & $377(43)$ \\
& $26(11)$ & $32(13)$ & $21(10)$ & $20(10)$ & $99(11)$ \\
$\begin{array}{l}\text { Nature of deaths not related to non-Hodgkin's lymphoma } \\
\text { Treatment related infection }\end{array}$ & $12(5)$ & $15(6)$ & $7(3)$ & $6(3)$ & $40(4)$ \\
$\begin{array}{l}\text { Treatment related, not an infection } \\
\text { Second primary tumour }\end{array}$ & $12(5)$ & $11(5)$ & $11(5)$ & $12(6)$ & $46(5)$ \\
Other* & 1 & 5 & 2 & 2 & $10(1)$ \\
\hline
\end{tabular}

${ }^{*}$ Accident and other medical cause unrelated to tumour or its treatment. latent interval for secondary leukaemias is four to six years and it therefore appears unlikely that many more of these will occur in this cohort.

The 608 children who were diagnosed from 1977 (when the UKCCSG was formed) onwards and who received radiotherapy or chemotherapy for non-Hodgkin's lymphoma were classified according to whether they were treated at a paediatric oncology centre under a consultant who was a member of the UKCCSG and whether they were treated in the UKCCSG nonHodgkin's lymphoma trials (including the $T$ cell trial and patients registered with the UKCCSG as receiving the modified first study protocol). The five year survival rate for the 484 UKCCSG patients was $61 \%$ compared with $41 \%$ for the 124 patients treated elsewhere. The five year survival for the 241 trial patients was $63 \%$, whereas for the 367 non-trial children it was $54 \%$. The actuarial risks of treatment related deaths were not significantly different between UKCCSG and non-UKCCSG patients $\left(\chi^{2}=0.39\right.$ on one degree of freedom) nor between trial and non-trial patients $\left(\chi^{2}=0.34\right.$ on one degree of freedom).

\section{Discussion}

This study has confirmed that the official statistics available on cause of death as determined from death certificates are inadequate for 
detecting treatment related deaths, even after the modification to coding of treatment related deaths introduced with the ninth revision of the International Classification of Diseases. Therefore if mortality is to be used as an outcome measure to detect severe treatment related effects, it is essential that all available sources of information are used to determine the precise cause of death.

During the period 1974-85 treatment for non-Hodgkin's lymphoma became increasingly intensive, producing a marked improvement in survival. The percentage of patients dying from causes other than non-Hodgkin's lymphoma did not increase during the study period, but as a result of the dramatic decrease in the percentage of patients dying from non-Hodgkin's lymphoma the proportion of the total number of deaths accounted for by causes other than nonHodgkin's lymphoma had doubled from $15 \%$ to $32 \%$.

Treatment related mortality from infection nearly halved during the study period, presumably as a result of the improvements in general supportive management and increased availability of therapeutic and prophylactic antibiotics and antiviral agents.

It is of concern that the non-infective, treatment related mortality remained constant, but also reassuring that it has not increased. The largest subcategory within this group was the metabolic disorder deaths. These deaths all occurred, soon after diagnosis, in children who were already unwell because of their tumour. It did seem, however, that medical intervention (an operation or starting chemotherapy) precipitated their deaths. Nearly half occurred after starting chemotherapy, mainly within 24 hours. The rest occurred during or soon after a diagnostic operation in children with extensive disease which affected the abdomen in all but one patient. Although tumour lysis can occur without any medical or surgical intervention there is also evidence that it can be precipitated by handling of the tumour during an operation. ${ }^{13}$ Over the past few years there has been an increasing awareness of the careful initial management that is required for children with non-Hodgkin's lymphoma who have extensive disease. In particular the gentle introduction of chemotherapy and also the increased use of fine needle biopsy guided by ultrasound or computed tomography instead of laparotomy should reduce mortality from metabolic disturbances in future years.

The treatment related deaths from renal disease include six patients where there was renal disease or obstructive nephropathy from an abdominal tumour. These patients were included because an operation seemed to precipitate their deaths, which were thus possibly avoidable. The deaths related to an anaesthetic included two patients with compromised airways from superior venous cava syndrome which had been diagnosed before the operation, one patient with an undiagnosed mediastinal relapse causing tracheal obstruction, and one patient who inhaled gastric contents during the operation.

It is impossible to classify all the treatment related deaths into avoidable or unavoidable, but there are a few that almost certainly were avoidable. These included the four anaesthetic related deaths and also the patient who died of pneumococcal meningitis following splenectomy who was not receiving penicillin prophylactically. It is likely that some of the deaths related to metabolic and renal disease were also avoidable.

Most of the treatment related deaths in this study occurred within a few months of diagnosis. There were only two deaths from cardiomyopathy at 15 and 30 months after diagnosis. Children who have been treated with doxorubicin (Adriamycin) apparently remain at risk of death from cardiomyopathy for many years ${ }^{14}$ and it is not yet possible to predict how many members of the study group will eventually die of treatment related cardiovascular problems. It is evident, however, that continued long term evaluation of these patients is essential not only for their care, but also for planning future chemotherapeutic treatment.

The occurrence of second primary neoplasms following childhood non-Hodgkin's lymphoma is already well documented, particularly among the patients included in the UKCCSG nonHodgkin's lymphoma I study. ${ }^{15}$ Of the 10 patients in this series, five have been reported previously ${ }^{15} 16$; the five previously unreported patients included three with acute myeloblastic leukaemia, one with osteosarcoma, and one with astrocytoma. This emphasises the point that the occurrence of second primary tumours in children treated for non-Hodgkin's lymphoma is a continuing problem and the long term risks of second primary tumours in patients who have received intensive treatment for non-Hodgkin's lymphoma are as yet unknown. Treatment for cancer with radiotherapy and chemotherapy, particularly the alkylating agents, is associated with an increased risk of developing a second primary tumour. ${ }^{3-5}$ There is mounting evidence that epipodophyllotoxins are implicated in the occurrence of secondary leukaemias following treatment for a variety of adult and childhood cancers and especially nonHodgkin's lymphoma. ${ }^{17-19}$ This is of particular relevance as teniposide, one of the epipodophyllotoxins, was part of the protocol in the UKCCSG non-Hodgkin's lymphoma trials. ${ }^{89}$ Children continued to be treated with these protocols after the official closure of the trials in 1983.

The difference in five year survival rate for children treated during 1977-85 in UKCCSG centres compared with those treated elsewhere was similar to that previously reported for $1977-84 .^{20}$ The risk of dying from a treatment related cause, however, did not vary significantly with the type of treatment centre or entry into trials. Despite apparently inadequate treatment outside paediatric oncology centres, the risk of death from a treatment related cause was just as high as for patients treated more effectively and presumably more aggressively in UKCCSG centres.

In conclusion, a substantial number of children diagnosed with non-Hodgkin's lymphoma during the period 1974-85 died from treatment related effects and as survival improves these 
deaths are becoming a larger proportion of the overall number of deaths. The number of deaths from infection is probably decreasing. Therefore further reductions in treatment related mortality are likely to depend on the prevention of deaths from metabolic and renal disorders, especially in children with intra-abdominal primary tumours, and in preventing deaths from complications of anaesthesia. As more is learnt about the aetiology of second primary tumours it may become possible to prevent some of them without compromising the present high survival rates for non-Hodgkin's lymphoma. Further improvements in survival for childhood non-Hodgkin's lymphoma will depend on maintaining the fine balance between the therapeutic value of intensive treatment and its potential harmful effects.

We thank the consultants and general practitioners who provided the information on which this paper is based. We are particularly grateful for the support we have had from the UKCCSG. We are grateful to the Office of Population Censuses and Surveys, the Information and Statistics Division of the Common Services Agency of the Scottish Health Service, regional cancer registries, and the National Health Service Central Registers for providing information on patients with childhood cancer. We express our thanks to $M$ Allen, E Mowat, $M$ Loach, and P Brownbill and to other members of the CCRG. We are indebted to our colleagues $M M$ Hawkins and G J Draper for their support and advice. This work was supported by the Oxford Regional Heal advice. This work was supported by the Oxford Regional Health Authority and by the Department of Health and the Scottish Home and Health Department, the Cancer Research Campaign and the
Leukaemia Research Fund. Dr J E Kingston is supported by the Imperial Cancer Research Fund.

1 Stiller CA, Bunch KJ. Trends in survival for childhood cancer in Britain diagnosed 1971-85. Br f Cancer 1990;62: 806-15.

2 Hawkins MM, Kingston JE, Kinnier Wilson LM. Late deaths after treatment for childhood cancer. Arch Dis Child 1990;65:1356-63.

3 Hawkins MM, Draper GJ, Kingston JE. Incidence of second primary tumours among childhood cancer survivors. $\mathrm{Br} \mathcal{J}$ Cancer 1987;56:339-47.

4 Tucker MA, Meadows AT, Boice JD, et al. Leukaemia after therapy with alkylating agents for childhood cancer. $\mathcal{F} \mathrm{Nat}$ Cancer Inst 1987;78:459-64.

5 Tucker MA, D'Angio GJ, Boice JD, et al. Bone sarcomas linked to radiotherapy and chemotherapy in children. linked to radiotherapy and chen

6 Saarinen UM, Rapola J. Inevitable and avoidable deaths in childhood ALL. Acta Paediatr Scand 1986;75:316-20.

7 Evans PM, Alberman E. Certified cause of death in children and young adults with cerebral palsy. Arch Dis Child 1990 65:325-9.

8 Mott MG, Eden OB, Palmer MK. Adjuvant low dose radiation in childhood non-Hodgkin's lymphoma. Br f Cancer 1984 50:463-9.

9 Mott MG, Chessells JM, Willoughby MLN, et al. Adjuvan low dose radiation in childhood T-cell leukaemia/lymphoma. Brf Cancer 1984;50:457-62.

10 Birch JM, Marsden HB. A classification scheme for childhood cancer. Int $\mathcal{f}$ Cancer 1987;40:620-4.

11 World Health Organisation. Manual of the international statistical classificatin of diseases, injuries and causes of death. 8th revision. Geneva: WHO, 1965.

12 World Health Organisation. Manual of the international statistical classification of diseases, injuries and causes of death. Statistical classification of diseases, injur

13 Lobe TE, Karkers MS, Kuster MD, Shenfelt RE, Douglass EC. Fatal refractory hyperkalaemia due to tumor lysis during primary resection for hepatoblastoma. 7 Pediat Surg 1990;25:249-50.

14 Steinherz LJ, Steinherz PG, Tan CT, Heller G, Murphy L. Cardiac toxicity 4 to 20 years after completing anthracycline therapy. $\mathcal{F A M A}$ 1991;266:1672-7.

15 Ingram L, Mott MG, Mann JR, Raafat F, Darbyshire PJ Morris Jones PH. Second malignancies in children treated for non-Hodgkin's lymphoma and T-cell leukaemia with the UKCCSG regimens. Br $\mathcal{Y}$ Cancer 1987;55:463-6.

16 Kingston JE, Hawkins MM, Draper GJ, Marsden HB, Kinnier Wilson LM. Patterns of multiple primary tumours in patients treated for cancer during childhood. Brf Cancer 1987;56:331-8.

17 Pui CH, Ribeiro RC, Hancock ML, et al. Acute myeloid leukaemia in children treated with epipodophyllotoxins for acute lymphoblastic leukaemia. N Engl f Med 1991;325: acute lymp $1682-7$.

18 Pui CH, Hancock ML, Raimondi SC, et al. Myeloid neoplasia in children treated for solid tumours. Lancet 1990;336: 417-21

19 Hawkins MM, Kinnier Wilson LM, Stovell MA, et al. Epipodophyllotoxins, alkylating agents, and radiation and risk of secondary leukaemia after childhood cancer. BMF 1992 304:951-8.

20 Stiller CA. Centralisation of treatment and survival rates for cancer. Arch Dis Child 1988;63:23-30. 